\title{
Principales patologías de degradación y técnicas de restauración de las vidrieras de hormigón
}

\author{
Pepe Cubillo
}

Resumen: El presente estudio se centra principalmente en las llamadas vidrieras de hormigón, su historia, técnica de realización, los materiales que las componen, las principales patologías de deterioro que les afectan y una serie de directrices básicas para afrontar las tareas de conservación y restauración. El objetivo es poner de relieve la necesidad de impulsar el estudio, catalogación, restauración, conservación y valoración de esta parte importante de nuestro patrimonio vidriero entre los diferentes agentes implicados: escuelas, instituciones culturales, organismos oficiales, historiadores, restauradores, conservadores y talleres de creación de nuevas vidrieras.

Entre las principales conclusiones que pueden extraerse en este documento destaca la vital importancia de realizar tareas periódicas de mantenimiento, pues de esta manera no sólo se garantiza una vida sana y duradera de la vidriera, sino que también pone de manifiesto que sin una regularidad en las inspecciones, los daños ocasionados pueden llegar a ser irreversibles.

Palabras clave: vidrieras, "dalle de verre", deterioro, patologías, técnicas de restauración, conservación, mantenimiento

\section{Main degradation dathologies and restoration techniques of concrete stained glass}

Abstract: This study focuses mainly on the so-called dalle de verre stained glass windows, their history, production techniques, the materials they are made of, their main deterioration pathologies and a series of basic guidelines for their conservation and restoration. The aim is to highlight the need to promote the study, cataloguing, restoration, conservation and valuation of this important part of our stained glass heritage among the different agents involved: schools, cultural institutions, official bodies, historians, restorers, conservators and stained glass workshops.

Among the main conclusions that can be drawn from this document is the vital importance of carrying out regular maintenance work, as this not only guarantees a healthy and lasting life for the stained glass, but also shows that without regular inspections, the damage to the objects can be irreversible.

Keyword: stained glass, "dalle de verre", deterioration, pathologies, restoration techniques, conservation, maintenance

\section{Principais patologias de degradação e técnicas de restauro de vitrais de cimento}

Resumo: Este estudo centra-se principalmente nos chamados vitrais de cimento, na sua história, na técnica de produção, nos materiais que os compõem, nas principais patologias de deterioração que os afetam e numa série de orientações básicas para enfrentar as tarefas de conservação e restauro.

O objetivo é evidenciar a necessidade de promover o estudo, a catalogação, o restauro, a conservação e a valorização desta importante parte do nosso património vidreiro entre os diferentes agentes envolvidos: escolas, instituições culturais, organismos oficiais, historiadores, restauradores, conservadores e oficinas para a criação de novos vitrais.

Entre as principais conclusões que podem ser extraídas deste documento, destaca-se a importância vital da realização de trabalhos de manutenção periódica, pois desta forma não só se garante uma vida saudável e duradoura dos vitrais, mas também mostra que sem inspeções regulares, os danos causados podem tornar-se irreversíveis.

Palavras-chave: vitrais, "dalle de verre", patologias de deterioração, técnicas de restauro, conservação, manutenção 


\section{Materiales}

\section{—Los materiales tradicionales}

- Vidrio: El componente principal del vidrio es la arena o el óxido de sílice $\left(\mathrm{SiO}_{2}\right)$, cuyo punto de fusión es de unos $1.710^{\circ} \mathrm{C}$. Esta temperatura tan elevada es generalmente muy difícil de obtener, por lo que para disminuirla se le añade sosa, que lo reduce hasta los $700-900{ }^{\circ} \mathrm{C}$, y óxido de calcio, que actúa como estabilizador del vidrio. La composición estándar para el vidrio común de vidrieras, el sílico-sódico-cálcico es aproximadamente: $69-75 \%$ de sílice $\left(\mathrm{SiO}_{2}\right), 12-15 \%$ de sosa $\left(\mathrm{Na}_{2} \mathrm{CO}_{3}\right)$ y $5-12 \%$ de óxido de calcio ( $\mathrm{CaO})$. El color del vidrio se obtiene mediante la adición de determinados óxidos metálicos en reducidas cantidades, generalmente inferiores a un $5 \%$.

Las dallas (del francés dalle que significa losa o placa) son los vidrios que se utilizan para la realización de las vidrieras de hormigón. Se diferencian de los vidrios utilizados tradicionalmente en las vidrieras emplomadas en sus dimensiones estándar, la paleta de color es generalmente más reducida, absorben más la luz, son muy resistentes a los impactos y su fabricación continúa siendo artesanal, no por soplado sino por colado en bandejas metálicas. [figura 1]

La dalla presenta una superficie ligeramente texturada creada intencionadamente durante su fabricación por contacto directo con la base del molde, y otra totalmente lisa. En el proceso de realización de la vidriera, la cara lisa estará en contacto con la lámina de metacrilato de $1 \mathrm{~mm}$, material que utilizamos en la actualidad como separador entre la vidriera y la mesa de trabajo, determinando también su posición en la arquitectura, situando preferiblemente la cara lisa hacia el exterior y la texturada hacia el interior. Escogemos esta posición no sólo porque va en consonancia con la superficie fina del hormigón (la textura del fraguado del hormigón sobre el metacrilato es siempre más liso y uniforme que el fraguado superior) sino porque esta cara

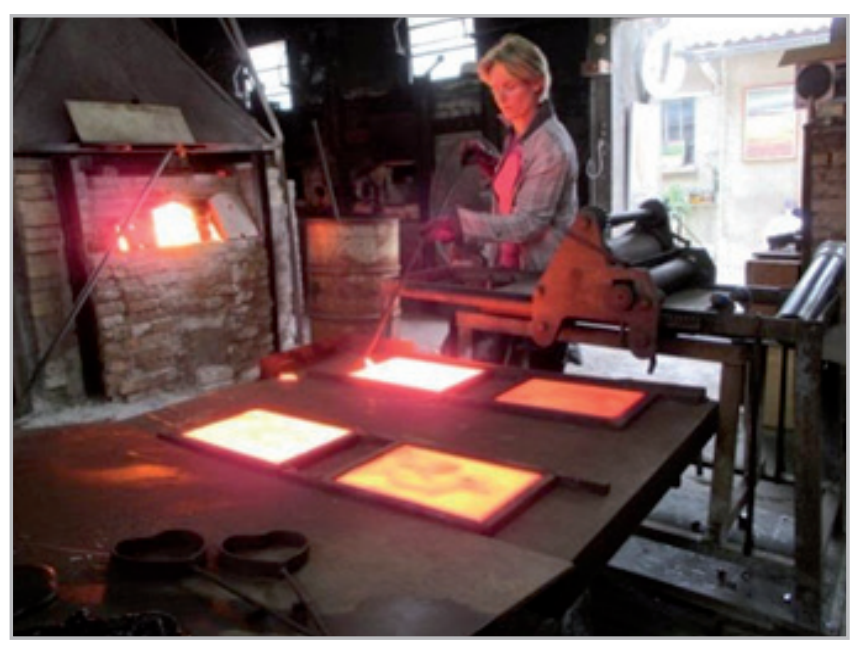

Figura 1.- Fábrica artesana, Société Albertini de la dalla retiene menos agua y refleja mejor la luz. Esta premisa puede verse afectada en caso de utilizar grisallas o efectuar desconchados, los cuales, en ambos casos, se realizan por la cara lisa que se posicionará hacia el interior.

- Hormigón armado: El hormigón armado es una mezcla integrada por cuatro componentes fundamentales: cemento Portland, agua, árido y las varillas de acero que forman las armaduras internas.

- El cemento Portland: Aunque fueron los ingleses Joseph Aspdin y James Parker quienes patentaron el cemento Portland en 1824, denominado así por su color gris verdoso oscuro similar a la piedra de Portland, se considera al químico francés J.L.Vicat como su creador. En 1818 Vicat estudia los aglomerantes naturales, estableciendo las bases científicas para la fabricación del cemento artificial. Sin embargo, la base del cemento moderno a escala industrial, con una base más científica, fue establecida en 1844 por Isaac Charles Johnson (1811-1911) al emplear temperaturas suficientemente altas para clinkerizar ${ }^{[1]}$ la mezcla de arcilla y caliza. Las fabricaciones de material calcinado a más alta temperatura daban un producto escorificado de color más oscuro, el cual tenía un endurecimiento más lento, con mayor hidraulicidad y alcanzaba resistencias mucho más elevadas. La función del conglomerante es la de unión de los áridos y la protección de la armadura frente a la corrosión y el resto de agentes agresivos.

- El agua: El agua permite que se produzcan las reacciones químicas necesarias para el posterior endurecimiento del cemento. Además, permite que la masa se pueda trabajar fácilmente. Sin embargo, la cantidad de agua que se emplee debe limitarse lo máximo posible. Como recomendación de carácter genérico el exceso de agua en el amasado disminuye enormemente la resistencia final, mientras que una escasez del agua de curado perjudica la hidratación y provoca retracción. La relación agua/ cemento está determinada entre $0.45 \mathrm{~L}$ (baja) y 0,52 L (alta) $x$ kg de cemento utilizado. La EHE ofrece algunas recomendaciones sobre el tipo de aguas utilizadas en la preparación del hormigón con la finalidad de evitar ataques ácidos. La EHE prohíbe el empleo de aguas ácidas obligando que su pH sea mayor o igual a 5. Un pH inferior puede ser perjudicial a la armadura debido a que la acidez del agua puede disolver la pasta endurecida del cemento, aumentando su poder disolvente al decrecer el $\mathrm{pH}$.

- Áridos finos o arenas: Se denominan áridos a los pequeños fragmentos (granulometría de $2-3 \mathrm{~mm} / \mathrm{mm} \varnothing$ ) de materiales duros, en general de arenas o rocas, que se introducen en la mezcla del hormigón junto al cemento y al agua para conferirle un mayor agarre y resistencia a la mezcla. Los más utilizados son la arena de rio lavada (cuarzo) y la granilla de mármol, que aumentan su resistencia y durabilidad. Son los encargados de conferir resistencia y durabilidad al hormigón, y son también los responsables de sus propiedades físicas, químicas y térmicas. 
- Varillas de acero: Proporcionan una mayor cohesión al conjunto y tienen la misión de resistir las tensiones de tracción y flexión que aparecen en la estructura, mientras que el cemento resistirá la compresión. En este sentido, el uso de varillas de acero convierte a este hormigón en hormigón armado. Para aquellas vidrieras muy expuestas a la humedad o situadas en zonas cercanas al mar es preferible utilizar acero inoxidable 316 para la armadura interna. Más adelante, en el apartado de alteraciones y patologías de deterioro, hablaremos sobre las propiedades del hormigón para proteger a las armaduras metálicas de la corrosión. En el caso que nos ocupa del uso de hormigón para la realización de vidrieras no es una excepción esta cualidad protectora, pero la fina capa que existe entre la superficie y las armaduras reduce esta protección, por lo que recomendamos, no sólo el uso de varillas de acero, sino también creemos beneficioso una imprimación anticorrosiva monocomponente basada en resinas epoxídicas y zinc para la protección de armaduras (Nitoprime Zincrich Plus ${ }^{\circledR}$ ). Otra posibilidad es el uso de varillas de acero inoxidable 304 o 316.

- Aditivos: Los aditivos son aquellos productos que añadidos durante la realización del hormigón permiten modificar sus propiedades, tanto químicas como cromáticas, ayudándonos a adaptarnos a cualquier tipo de proyecto de una forma susceptible de ser prevista y controlada. El más comúnmente usado entre los creadores de nuevas vidrieras de hormigón es el SikaLatex ${ }^{\circledR}$, una emulsión sintética de estirenobutadieno, cuyas propiedades más importantes son las siguientes: mayor elasticidad y resistencia a la tracción, mayor impermeabilidad, mayor plasticidad y trabajabilidad. mayor resistencia química, menor riesgo de fisuras, mayor resistencia a la abrasión

\section{-Nuevos materiales}

- Mortero de reparación clase R4: Esta nueva línea de morteros epoxi son empleados tanto para la reparación como para la realización de nuevas vidrieras. Estos morteros sólo necesitan agua para ser utilizados, eliminando la necesidad de utilizar agregados de áridos y armadura interna, aunque nosotros sí recomendamos el uso de varillas, al menos en una tercera parte. Además ofrecen nuevas propiedades en su composición, fruto de un mejor conocimiento de los materiales, lo que nos aporta más garantías de conservación, alargando así la vida de las vidrieras y reduciendo las tareas de mantenimiento. Entre las características más importantes de estos morteros de resina epoxi destacamos: permeables al vapor de agua, alta resistencia a la carbonatación, resistentes a ciclos de hielo-deshielo, regeneración del hormigón, retracción compensada, resistentes a la intemperie.

- Resinas epoxi: Artistas franceses como Frédérique Duran experimentaron ya por los años 60 del siglo XX con las primeras resinas epoxi como posible sustituto del hormigón armado en las vidrieras. Asimismo, en Inglaterra, en la misma época, los artistas John Piper y Patrick Reyntiens, experimentaron con el uso de resinas en la famosa linterna de la Catedral Metropolitana de Liverpool. Con el paso del tiempo se comprobó que estas resinas no proporcionaban la estabilidad adecuada, degradándose rápidamente y generando problemas serios de conservación. Las resinas actuales, sin embargo, al igual que los morteros de reparación $\mathrm{R} 4$, vienen a cubrir las carencias de sus predecesores, y entre sus características más importantes podemos destacar: resistencia completa a la humedad, resistencia a la adherencia de 2.000 psi, baja contracción, gran estabilidad dimensional, resistencia a los agentes químicos, alta resistencia mecánica, capacidad de unir materiales de diferente naturaleza

\section{Técnica de realización}

Físicamente, la vidriera de hormigón es una vidriera robusta y pesada, pudiendo llegar a los $35-40 \mathrm{~kg} / \mathrm{m}^{2}$. Estas vidrieras se integran con la arquitectura, hasta el punto que ya no hablamos de ventanales para referirnos a los espacios que tradicionalmente ocupaban las vidrieras emplomadas, sino de muros de luz. Estas características también han contribuido a ubicarlas en nuevos espacios, como plantas bajas directamente a pie de calle sin necesidad de protección exterior y a experimentar con nuevas geometrías, creando vidrieras con formas cóncavas, convexas o incluso semiesféricas, en forma de cúpulas. De igual modo, en los últimos años se ha abandonado su condición natural de muro de luz y se ha experimentado con resultados muy positivos en un nuevo campo como es el de la escultura en vidrio.

Desde un punto de vista estético, la evolución de la vidriera de hormigón es fascinante. Los diseños de las primeras vidrieras estaban en parte inspirados en la estética del mosaico, generando muy rápidamente un lenguaje único de expresión artística a través del vidrio y la luz. Asimismo, al contrario que la vidriera emplomada, donde prácticamente toda ella es luz, las vidrieras de hormigón integran perfectamente las fuertes líneas opacas del cemento como una parte más a tener en cuenta a la hora de elaborar el diseño.

\section{- Proceso de Realización}

A continuación haré una breve descripción técnica del proceso de realización tradicional, pensado para el uso de hormigón armado, tal y como mi maestro Antoni Castejón me lo enseñó. Esta forma de proceder puede verse alterada entre diferentes talleres o por la utilización de nuevos materiales como los cementos de reparación o resinas.

1. Como con cualquier otro tipo de vidriera, comenzamos con la ejecución del diseño, creando el boceto a escala $1: 10$, que trasladaremos a escala real para obtener las plantillas de corte del vidrio mediante papel vegetal. En el diseño de la vidriera tendremos en cuenta las varillas 

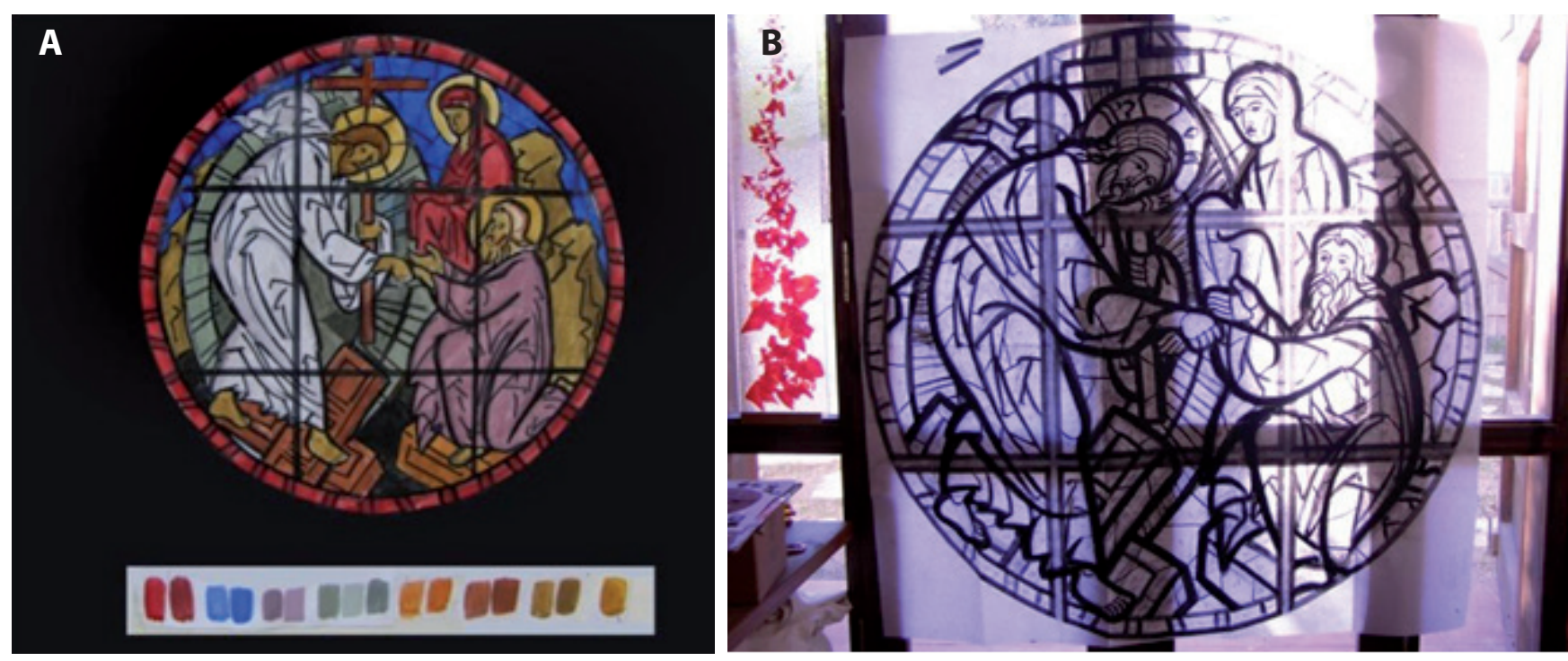

Figura 2.- A) Boceto. B) Diseño a escala real

de acero de $6 \mathrm{~mm} \varnothing$, las cuales aconsejamos situarlas cada $20 \mathrm{~cm}$ aprox. Las varillas se soldarán entre sí, y todo el conjunto a una pletina perimetral de acero de aproximadamente $2,5 \mathrm{~cm}$ de ancho $\times 0,3 \mathrm{~mm}$ de grosor que hará la función de contención del hormigón, refuerzo y premarco, facilitando asimismo su transporte, montaje y futuro desmontaje [figura 2]. Actualmente, en mis propias obras, estoy descartando esta pletina perimetral de acero en los nuevos proyectos por el propio hormigón. Realizo la contención con listones de madera y de esta manera toda la estructura de varillas de acero queda protegida en el interior. Pensamos que la contención rígida de la pletina perimetral de hierro reduce la flexibilidad del panel aumentando la posibilidad de generar más fracturas en los vidrios y en el hormigón. La eliminación de estas pletinas reduce la posibilidad de corrosión de las varillas de acero, así como el proporcionar una mayor flexibilidad del panel en los procesos de congelación-descongelación en el interior de las fracturas del hormigón o por una insolación excesiva sobre los materiales.

2. El corte de la dalla de vidrio puede realizarse bien mediante disco de diamante refrigerado por agua o con el método tradicional. Para proceder a cortar la dalla de forma tradicional marcamos la línea con una rulina, a continuación apoyaremos la cara opuesta sobre una cuña de hierro fijada a un bloque de madera, coincidiendo con la línea de corte, y finalizaremos con un golpe seco, sobre la cara superior, con un martillo con cabeza de tungsteno. En esta parte del proceso es posible proporcionar a los vidrios cortados una bella cualidad estética única, brillos y matices característicos sólo de las vidrieras de hormigón, como son los desconchados y descamaciones realizadas por un golpe seco con el martillo en el lateral de la dalla y en determinado ángulo. Finalmente, protegeremos mediante masilla o plastilina los desconchados durante el vertido de cemento o resina. La razón de esta práctica es la de mantener uniforme el grosor del hormigón en todo el panel, porque al realizar desconchados reducimos su grosor en estas zonas concretas de la Dalla. [figura 3]

3- Sobre una mesa o tablero pondremos el dibujo a escala real y sobre éste un metacrilato transparente de $1 \mathrm{~mm}$ de grosor que actuará como separador. Fijaremos el premarco perimetral con la trama interna de varillas de hierro (a partir de ahora llamada armadura interna), coincidiendo con el dibujo. Por último las piezas de vidrio irán pegadas con pegamento universal al metacrilato para evitar su movimiento durante el vertido del hormigón. Es muy importante, a fin de evitar futuras fracturas en los vidrios, que estos nunca entren en contacto con las varillas de acero, permitiendo al cemento penetrar entre ambos. [figura 4]
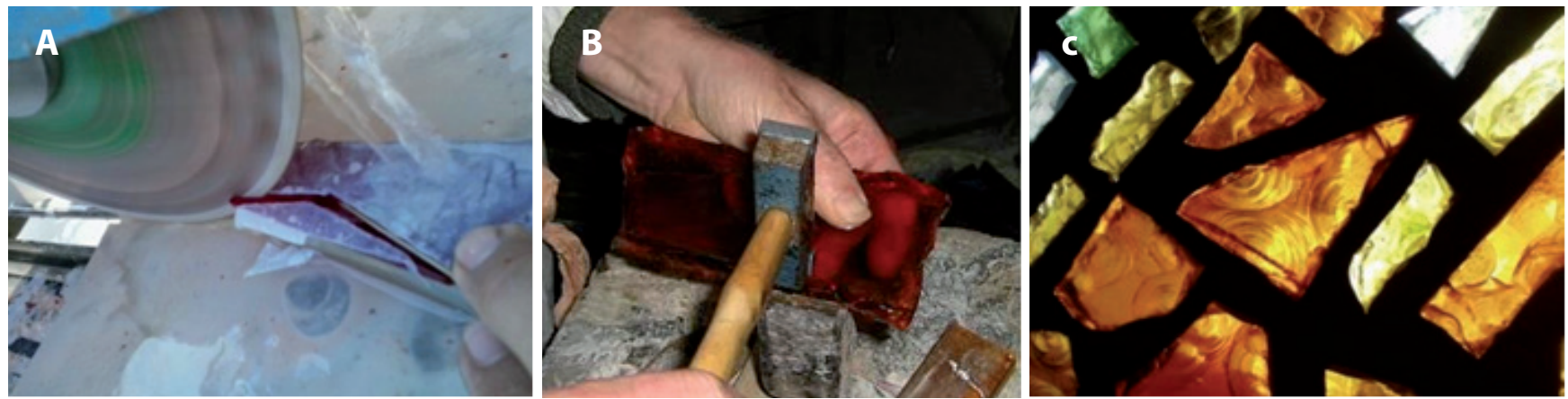

Figura 3.- A) Corte Disco. B) Corte Manual. C)Delalle desconchados 

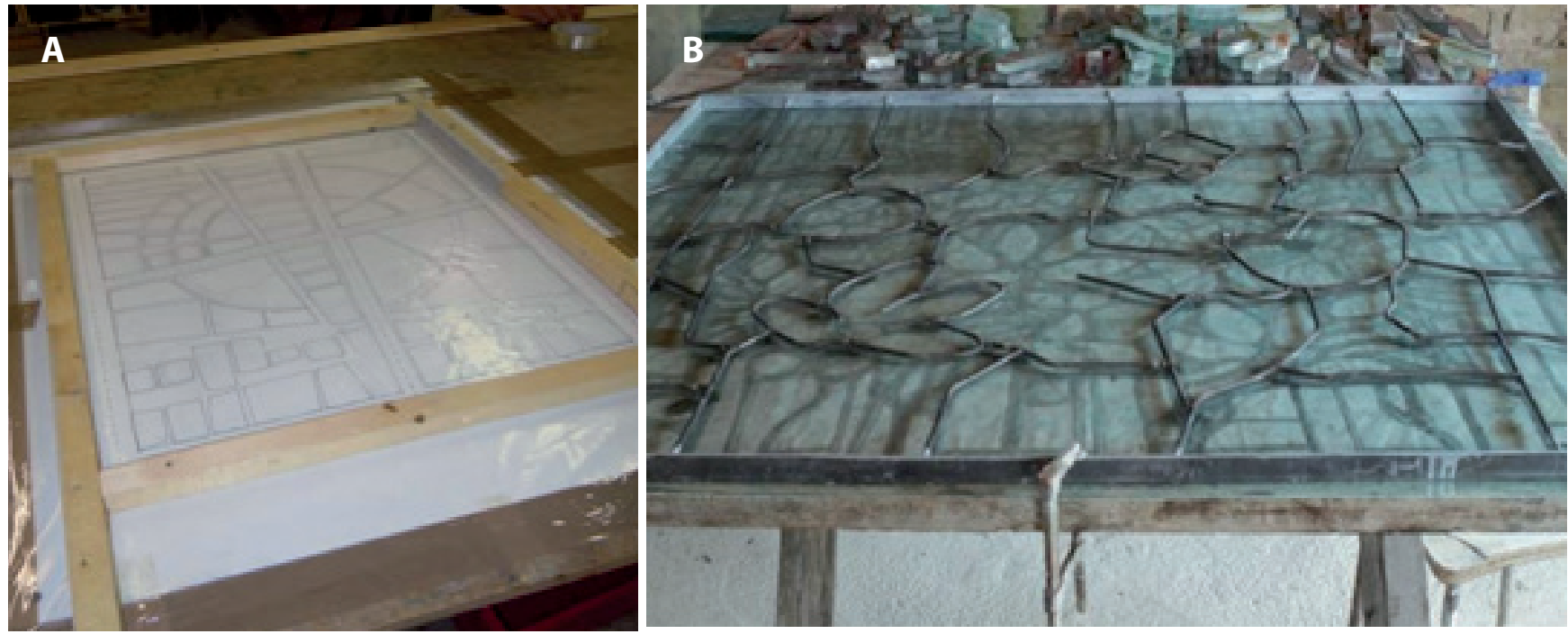

Figura 4.- A) Premarco provisional madera. B) Premarco fijo hierro

4. Prepararemos la mezcla adecuada de cemento, arena y agua que verteremos cuidadosamente a fin de evitar burbujas de aire, distribuyéndola cuidadosamente por toda la superficie hasta llegar a cubrir por completo la altura de las dallas. Cuando empiece a fraguar, entre 10 y 20 horas dependiendo de la temperatura, tipo de mezcla o cemento utilizado, retiraremos la capa superficial de hormigón para proceder a su limpieza con serrín y cepillo. Si hemos utilizado listones de madera para la contención perimetral del hormigón los retiraremos después de la limpieza. Concluiremos el proceso de fraguado volteando la vidriera y limpiando los restos de hormigón pasadas las 48 horas. La superficie de la vidriera donde el hormigón ha fraguado en contacto con el metacrilato se instalará hacia el exterior del edificio. El acabado liso de esta cara soportará mejor las condiciones de agua y humedad, facilitando su secado, así como un menor acumulamiento de suciedad. [figura 5]

Preparación del Hormigón: 4 partes de arenilla de mármol, 1 parte de cemento y una relación de agua entre 0,45 a 0.52 Litros $x \mathrm{~kg}$ de cemento dependiendo de los condicionantes atmosféricos a los que estará sometida la vidriera. Opcionalmente, para un acabado oscuro añadiremos tinte universal concentrado negro, y para un acabado en blanco es preferible sustituir el cemento gris por blanco.

\section{Diseño estructural}

Consideramos importante mencionar en este estudio la importancia del diseño estructural de la vidriera como elemento imprescindible para prevenir determinadas patologías de degradación así como facilitar su intervención en futuras tareas de conservación y restauración. El proceso de diseño de los marcos de acero inoxidable que soportarán los diferentes paneles que forman la vidriera debe lograr una combinación armónica entre el camino intuitivo y el científico, en la búsqueda de la proporción correcta. Para proyectos de gran envergadura, este debería ser un trabajo interdisciplinar llevado a cabo entre el técnico especializado y un profesional vidriero y teniendo en cuenta las premisas de funcionalidad, seguridad y desmontaje, tanto de paneles independientes como del conjunto de la obra.

\section{Instalación de la vidriera a la estructura}

Tradicionalmente, la mayoría de las vidrieras de hormigón se han anclado directamente a la obra con cemento, sin necesidad de estructuras ni juntas de dilatación. La creencia en la fortaleza y durabilidad del hormigón estaba muy extendida, y nada hacía pensar en la aparición de patologías
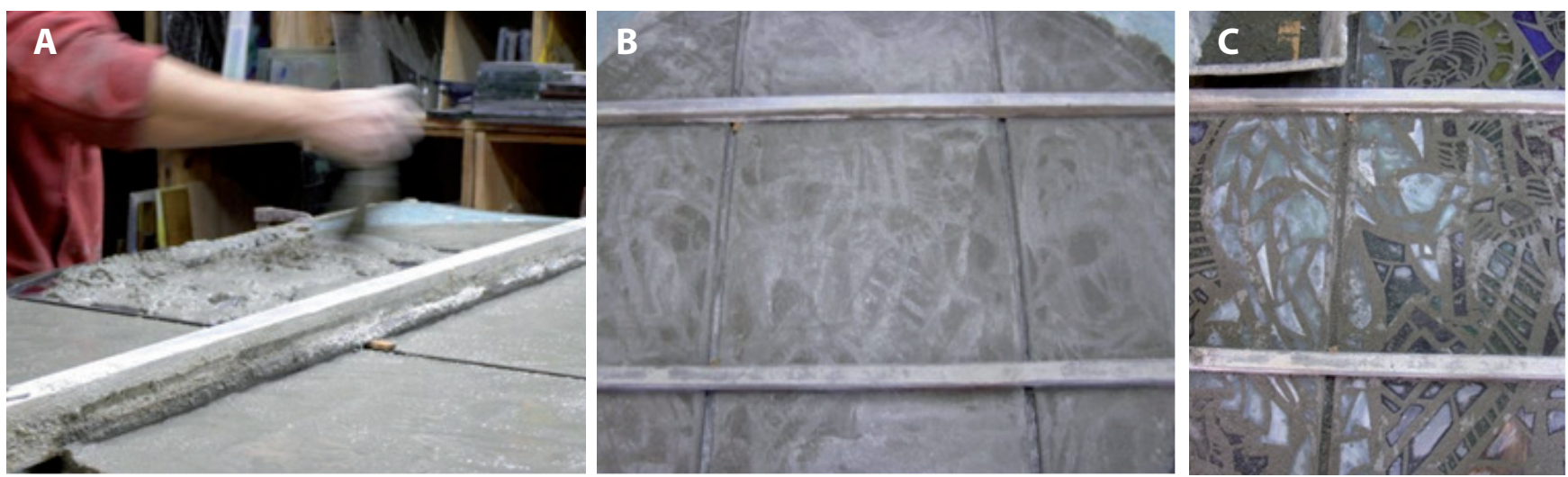

Figura 5.- A) Vertido cemento. B) Fraguado cemento. C) Limpieza cemento 
graves de deterioro, pero, como con todos los materiales, el hormigón no está exento de sufrir alteraciones.

Estas prácticas han dificultado enormemente las tareas de desmontaje de las vidrieras para su posterior restauración en el taller. Asimismo, la ausencia de una junta de dilatación entre la vidriera y la estructura de la obra provoca que los pequeños movimientos estructurales del edificio afecten negativamente a la vidriera, como veremos más adelante en el apartado 7 de alteraciones y patologías de deterioro.

Tanto las nuevas vidrieras de hormigón como aquellas que hayan sido restauradas, si carecían de marcos de acero, deberían ser instaladas preferentemente dentro de nuevas nuevos marcos de acero anclados a la obra y contar con juntas de dilatación de poliuretano internas alrededor de la vidriera. También es aconsejable diseñar un sistema funcional, seguro y reversible para facilitar su desmontaje en futuras tareas de restauración o conservación. [figura 6]

Otra característica que también hemos observado en el sistema tradicional de fijación de grandes vidrieras de hormigón formadas por diferentes paneles era
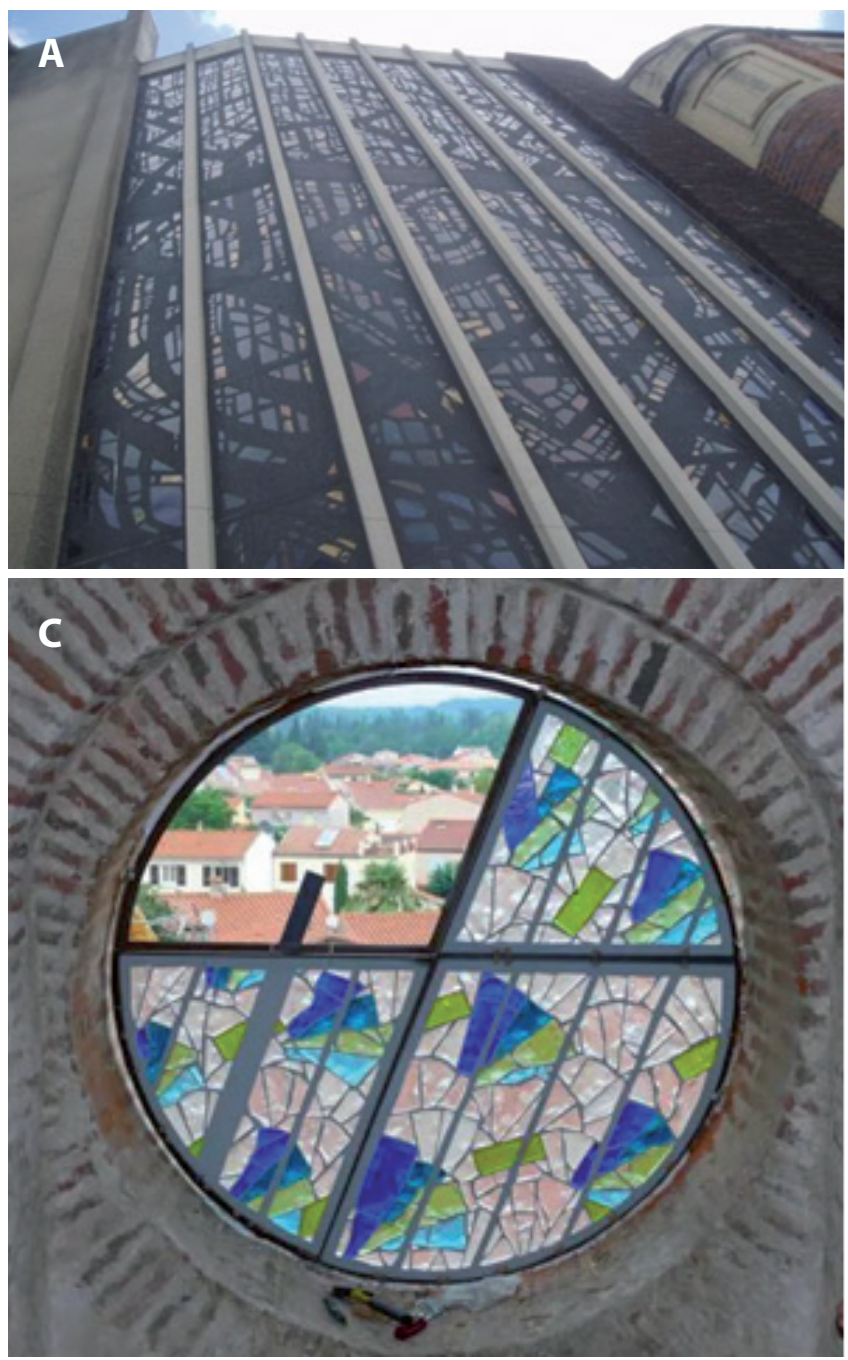

Figura 6.- A) St Andrew's Methodist Church in Worcester. B) Clotildel Gontel, 2019. Eglésie Palau-de- vidre la posibilidad de suprimir las estructuras de acero que soportan los diferentes paneles, eliminado así la geometría y simetría que estas creaban. Esta opción es sin duda muy interesante estéticamente, pero, como hemos descrito anteriormente, dificulta enormemente actuar sobre paneles independientes. De esta manera la vidriera se convertía en un todo. En este sistema, los paneles se iban montando unos sobre otros, soldados entre sí por las pletinas exteriores o ligados con cemento. Estos no necesariamente debían tener contornos rectos, pudiéndose encastar entre sí en diferentes formas geométricas. La única premisa que todavía hoy en día es válida es la referente a la superficie máxima que debería tener cada panel. En este sentido, no es recomendable que estos sean superiores a $1 \mathrm{~m}^{2},(35-40 \mathrm{~kg}$ aprox.), y preferiblemente que se mantengan entre 0,6 y $0,8 \mathrm{~m}^{2}$, unas proporciones y peso que facilitan su adecuada manipulación y montaje. [figura 7]

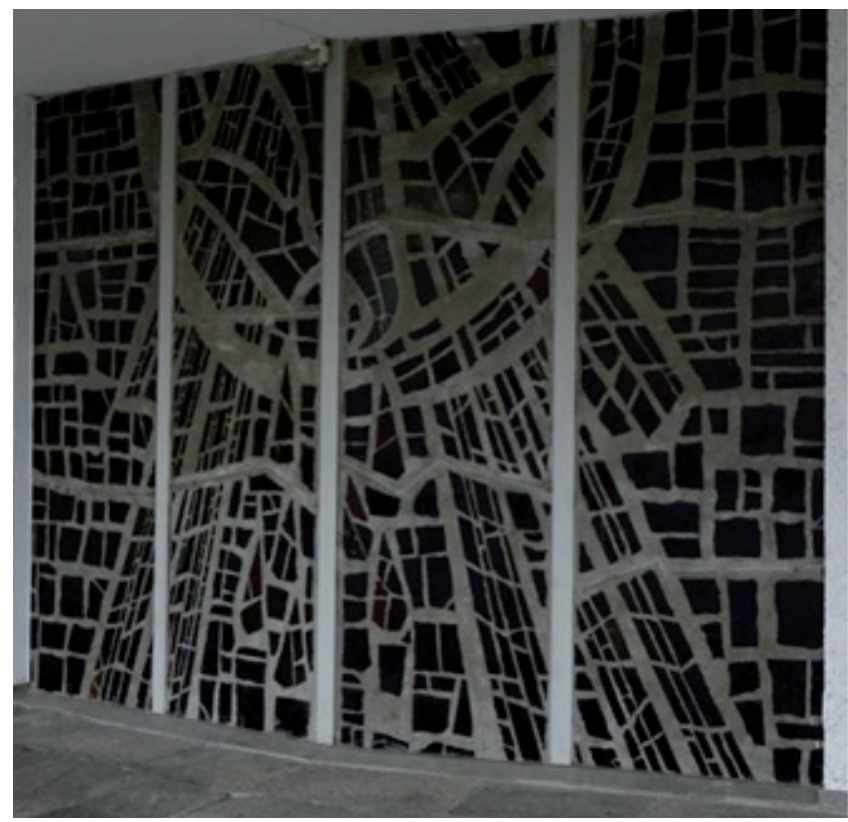

Figura 7.- Erwin Lutz-Waldner, 1967. Kirche St. Josef

Otros problemas derivados por la superposición de paneles es el estrés por carga de peso, o fatiga estática, que es una disminución de la resistencia de los materiales en el tiempo, afectando significativamente al vidrio. Se ha comprobado que los vidrios de los paneles inferiores pueden sufrir una mayor cantidad de grietas y roturas debido al peso que deben soportar. Asimismo, otro fenómeno detectado en los paneles inferiores son los abombamientos. Estos se producen cuando la presión que han de soportar es superior a la fuerza que pueden resistir y comienzan a abombarse. Este es un camino de no retorno que hace necesario actuar rápidamente, pues la integridad de la vidriera está en peligro, así como el riesgo de desprendimientos. Este tipo de patología sólo ha sido constatada en vidrieras de hormigón realizadas con resinas. [figura 8] 

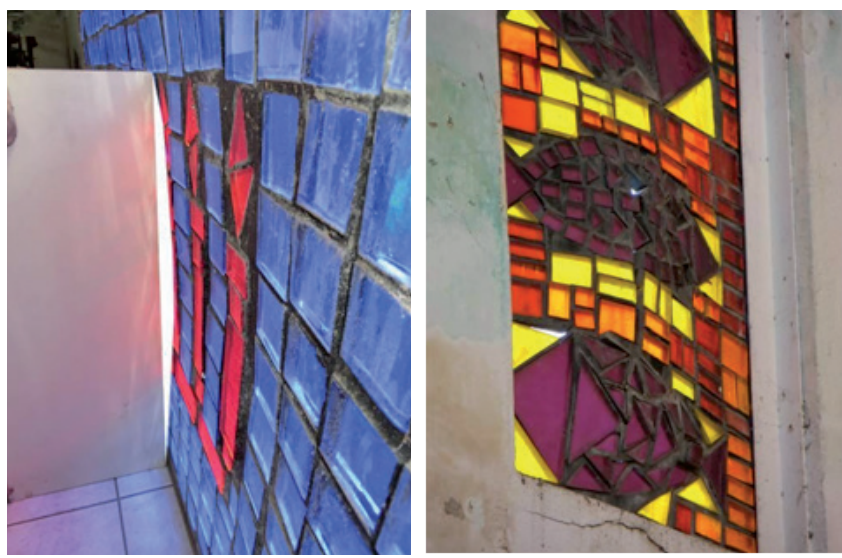

Figura 8.- Vidrieras de resina. Abombamientos. L'EGLISE ST ANDRE. Guadalupe. (Carlo Roccella

En la actualidad se ha producido una transformación técnica, fruto de la necesidad natural de un mayor refinamiento estético, un mejor conocimiento de los materiales tradicionales y sus patologías, y la aparición de nuevos materiales. En efecto, hoy día conocemos mejor cómo se comporta el hormigón y existen nuevos productos relacionados con el cemento, como son los nuevos morteros de reparación. Asimismo, las resinas epoxi de última generación, utilizadas tanto en restauración como en obra nueva, ofrecen nuevas soluciones a los problemas de conservación que sufren algunas de las vidrieras de hormigón más antiguas.

En la práctica, deberemos tener muy en cuenta las particularidades de cada proyecto y decidir correctamente la elección de materiales, técnicas de fabricación y procedimientos de ejecución, ya que estas decisiones afectarán a la vidriera durante toda su vida útil. Sin embargo, estas dificultades no deberían echarnos para atrás, más bien al contrario, deberían suponer un aliciente para fomentar en la investigación de esta técnica tan poco estudiada.

\section{Alteraciones y patologías de deterioro}

Como ya hemos mencionado anteriormente, los estudios científicos sobre los diferentes materiales, sus patologías y las posibles vías de actuación en este tipo de obras son muy escasas. Disponemos, eso sí, de una extensa información actualizada, particularmente sobre el uso del hormigón, cementos de reparación y resinas epoxi, la cual profundiza sobre sus patologías de deterioro y técnicas de restauración, extrapolables en muchos casos también a este tipo de vidrieras. En este sentido, es importante tener en cuenta que estos estudios nunca se han realizado teniendo en cuenta las particularidades de las vidrieras de hormigón.

Aunque las primeras vidrieras realizadas con esta técnica tienen ya casi 100 años, no es hasta después de la segunda guerra mundial, en la década de los años 60 del siglo XX, cuando comienza a haber un incremento notable en la utilización de esta técnica. Así pues, no es de extrañar que las primeras intervenciones de mantenimiento o restauración comenzaran hace no más de 30 años, por lo que realmente se trata de un campo joven y en pleno desarrollo. Si bien todavía no disponemos de un protocolo oficial de intervención, si podemos enumerar, consensuar y analizar, entre los profesionales que nos dedicamos a la realización de vidrieras de hormigón, una serie de patologías de deterioro, detectadas en base a nuestra propia experiencia. Para comprender las causas de deterioro de las vidrieras de hormigón deberemos prestar atención al comportamiento de sus diferentes materiales, así como a los factores externos y a las técnicas empleadas.

\section{Causas y efectos generales de deterioro}

\section{- Las propiedades químicas y físicas de los distintos elementos}

La composición química y las propiedades físicas de los diferentes materiales utilizados en la elaboración de vidrieras, como el hormigón armado tradicional, los morteros de reparación R4, las resinas epoxi y las dallas, condicionan irremediablemente el tipo y el grado de su deterioro. Es importante poner especial atención en la preparación del hormigón armado, pues es el único elemento en el que resulta extremadamente importante el proceso de elección, mezcla, preparación y curado de los diferentes materiales que lo componen (cemento, agua, áridos, armaduras internas y aditivos). Las técnicas utilizadas en su fabricación y el procedimiento de ejecución resultarán en un hormigón más o menos duradero, que soporte la exposición a determinadas condiciones ambientales, que proteja a las armaduras contra la corrosión y que en definitiva tenga una durabilidad lo mayor posible.

Los nuevos morteros de reparación y las resinas son materiales relativamente modernos, de altas prestaciones $y$ especializados para cada tipo de aplicación, ya sea obra nueva o restauración y conservación, por lo que deberemos conocer sus propiedades químicas y físicas y elegir los que mejor se ajusten a las características del proyecto y las condiciones climáticas de la zona. Si bien la actual composición de sílicesódico-calcio de las dallas nos garantiza una gran estabilidad química en el tiempo, éstas no están exentas de daños por agentes físicos externos, como impactos, bruscos contrastes de temperatura, etc., o por recocidos inadecuados en su realización, los cuales pueden provocan tensiones internas.

\section{- La alteración atmosférica o meteorización. Agresividad del ambiente de exposición}

Para evitar los efectos de este ataque resulta fundamental que en la etapa de diseño de la vidriera se conozcan las condiciones ambientales a las que van a estar sometidos los materiales, ya que, dependiendo de ellas, habrá que elegir el tipo de cemento, áridos, relación agua/cemento, grado de consolidación, curado y protección que tendrá el hormigón. La relación agua/cemento constituye un parámetro que 
desempeña un papel esencial en el proceso de curado y en su resistencia, durabilidad y retracción posteriores. A menor agua en relación al cemento, mayor será su resistencia a la compresión, menor su fluidez o trabajabilidad y mayor su durabilidad. Asimismo, al poseer menos agua, el hormigón tiene también menor cantidad de poros y vasos capilares que se forman durante su evaporación y por donde pueden penetrar los agentes agresivos cuando el hormigón no está protegido de los factores climáticos, y atacar a las armaduras. Por ello, en condiciones climáticas extremas deben utilizarse relaciones agua/cemento bajas, y en condiciones moderadas estas relaciones pueden incrementarse. La relación agua/ cemento está determinada entre 0.45 litros (baja) y 0,52 litroa (alta) $x \mathrm{~kg}$ de cemento utilizado.

Para que se produzca cualquier ataque químico resulta fundamental la presencia de agua, ya sea en forma líquida o gaseosa, porque es la encargada de la disolución de los componentes agresivos. Lamentablemente no disponemos de ningún estudio científico específico sobre los efectos del agua de condensación en las vidrieras de hormigón. Este fenómeno natural ocasionado por un contraste de temperatura y humedad sobre ambas caras de la vidriera podría acelerar cualquier ataque químico tanto en el vidrio como en el hormigón.

- Congelación: Las vidrieras instaladas a la intemperie en climas donde las temperaturas descienden con frecuencia por debajo de los cero grados, pueden originar la absorción de agua en el interior del hormigón, seguido de las consiguientes fases de congelación y descongelación, las cuales pueden provocar fracturas en el mortero. Un aumento del 9\% en el volumen del agua al congelarse provoca tensiones en el hormigón, pudiendo resultar en daños irreversibles. Pero lo realmente peligroso es la repetición de este fenómeno en el tiempo. En este sentido, recomendamos relaciones agua/cemento bajas, el uso de agentes aireantes, un curado adecuado que reduzca la porosidad del hormigón y la colocación de la cara lisa de la vidriera siempre hacia el exterior.

Los aditivos aireantes proporcionan al hormigón aire en forma de minúsculas burbujas que rompen la continuidad de los poros capilares, con lo cual éstos resultan más impermeables, menos absorbentes por capilaridad y resistencia a las heladas, al actuar las burbujas como cámaras de expansión cuando se hiela el agua contenida en los capilares. Los aditivos aireantes tienen además un papel secundario de lubricante sobre el hormigón fresco, es decir, ejercen una función de fluidificante que permite reducir la relación agua/cemento y una determinada cantidad de áridos. Todo esto se traduce en un aumento de resistencias mecánicas que compensa en cierta medida la disminución a que da lugar la inclusión del aire.

- Calor: el cemento, el vidrio y el acero (con un grosor de material similar) tienen casi el mismo coeficiente de dilatación. Sin embargo, los vidrios de diferentes colores se calientan de manera dispar dependiendo de la intensidad de la luz, resultando en distintos niveles de dilatación. Este ligero aumento de volumen puede conducir al desconchado y fisura del vidrio y a la aparición de grietas finas en el cemento, que contribuyen a la absorción de agua. En el caso de vidrieras con una mayor exposición a la radiación solar se recomienda sustituir el cemento gris por blanco (o bien pintar la cara exterior de la vidriera con Sikagard $-670 \mathrm{~W}^{\circledR}$ de color blanco). Asimismo se recomienda, en la medida de lo posible, evitar la elección de vidrios oscuros de gran tamaño y la colocación de la cara brillante y lisa de la dalla hacia el exterior (generalmente es la posición natural de la dalla en la vidriera).

Todas las resinas se alteran con el tiempo y las elevadas temperaturas. En este sentido, un tema muy poco estudiado en este tipo de obras es el efecto de las radiaciones solares sobre las resinas utilizadas en sustitución del cemento. Otra medida que nos parece válida para reducir los efectos de la radiación solar es la instalación de un acristalamiento isotérmico ventilado con el aire procedente del interior del edificio. Este sistema, que hasta donde alcanza nuestro conocimiento no ha sido utilizado hasta la fecha en este tipo de vidrieras, conseguiría en gran parte igualar la temperatura y humedad en ambas caras de la vidriera.

\section{- La orientación geográfica}

A lo largo de la historia la orientación geográfica de las vidrieras en el edificio ha desempeñado tradicionalmente un papel importante, tanto en su diseño como en su iconografía. El hecho de que las caras sur reciban una mayor insolación y las norte sean las más frías influye claramente en la elección de la gama cromática utilizada por parte del vidriero. Este fenómeno tiene también su influencia en las posibles patologías de deterioro que puedan producirse. Así pues, el aumento de la temperatura en las vidrieras orientadas hacia la cara sur puede producir desconchados en el vidrio y grietas en el cemento. Por el contrario, las vidrieras orientadas hacia la cara norte acumulan mayor humedad, pudiendo resultar en la formación de agua de condensación, biodeterioro, ataque químico y daños por congelación.

\section{- El efecto antrópico}

Son todos aquellos daños ocasionados por la acción humana: vandalismo, vibraciones del tráfico terrestre, aéreo o campanarios, el hollín de las velas, guerras, etc. Las intervenciones de restauración y conservación incorrectas pueden ser asimismo importantes factores de deterioro. Sin embargo, el problema principal radica en la ausencia de inspecciones y operaciones de mantenimiento regulares. Estas tareas están muy poco difundidas en el campo de las vidrieras y del patrimonio en general, a la vez que la legislación al respecto es absolutamente nula. Esta situación se agrava con el hecho de que en la mayoría de los casos los propietarios o custodios de los edificios donde se encuentran estas vidrieras no suelen estar preparados para detectar los signos y las consecuencias del deterioro. Como consecuencia, no es frecuente recurrir a un especialista 
hasta que el problema resulta obvio, momento en el que la reparación es ya muy costosa.

\section{— El deterioro biológico o bioalteración}

Cuando confluyen las circunstancias adecuadas, los agentes biológicos pueden afectar gravemente la vida útil de los materiales que forman parte de nuestro patrimonio. Si bien tanto en el campo de la construcción como en el de las vidrieras tradicionales emplomadas existen estudios sobre este tema, en el caso de las vidrieras de hormigón no hemos logrado encontrar información alguna sobre sus posibles efectos. Aun así, es posible extrapolar ciertos datos de un soporte a otro.

En líneas generales, el deterioro biológico sobre vidrieras tradicionales puede ser causado por micro y por macro organismos y puede producirse mediante mecanismos físicos y químicos. Los microorganismos son sin embargo los más frecuentes y por tanto los más estudiados en el campo de las vidrieras, dentro de los cuales se destacan las bacterias, cianobacterias, algas y hongos. Si las circunstancias son las adecuadas, estos organismos son capaces de deteriorar el cemento y el vidrio.

Lasalgasycianobacterias secretan sustanciasmucilaginosas que sirven para que estos microorganismos retengan la humedad necesaria. Dichas sustancias pueden reaccionar con los materiales, alterándolos. Los hongos y líquenes también pueden ocasionar un daño por acción mecánica, ya que sus hifas (los filamentos que los constituyen) van penetrando en el sustrato. Además, generan ácidos orgánicos como el ácido oxálico, que pueden erosionar la superficie del vidrio. La presencia de estos organismos se ve favorecida por unas condiciones concretas como son: una humedad relativa elevada (superior a un 70\%), unas temperaturas elevadas (próximas a los $30^{\circ} \mathrm{C}$ ) y un $\mathrm{pH}$ del agua condensada sobre el vidrio de entre 4 y 6 .

Otros agentes de deterioro de gran importancia pueden ser las aves. Cuando se establecen en un edificio, las deyecciones que generan pueden provocar un ataque de tipo tanto ácido como básico. Por otra parte, esas mismas deyecciones son un medio ideal que favorece el desarrollo de bacterias que a su vez deterioran los materiales.

\section{- Catástrofes naturales}

La fortaleza natural atribuida a las vidrieras de hormigón no les excluye de padecer las consecuencias desastrosas que los fenómenos incontrolados de la naturaleza, como movimientos sísmicos, terremotos, incendios, huracanes, tornados, etc., pueden tener sobre los edificios $y$, en particular, sobre las vidrieras, afectando en la mayoría de los casos a la estructura de hormigón. En este sentido es importante destacar que las vidrieras de hormigón son estructuras rígidas y no presentan la flexibilidad y capacidad de absorción de movimientos de las vidrieras emplomadas.

\section{- Las condiciones del edificio}

Como en el caso anterior, este factor puede afectar en la mayoría de los casos a la estructura de hormigón de la vidriera. Movimientos en la cimentación, originado por posibles fallamientos del subsuelo o de defectos estructurales del propio edificio, pueden ocasionar alteraciones en los marcos o directamente sobre la vidriera. Las consecuencias pueden llegar a ser fracturas estructurales del hormigón, fracturas de vidrios, abombamientos de los paneles (vidrieras de resinas) y, en última instancia su desprendimiento. Para reducir el impacto del movimiento estructural de los edificios sobre las vidrieras de hormigón es importante tener en cuenta la creación de juntas de dilatación adecuadas, las cuales absorberán este tipo de movimientos. Otro factor a tener en cuenta son las posibles filtraciones de agua y humedades derivadas de un mal estado de las cubiertas o de las bajantes.

\section{— Fatiga natural de los elementos de la vidriera}

La fatiga se define como la pérdida de propiedades de un material debido a la actuación de una carga repetida o a la exposición prolongada a determinadas condiciones, las cuales pueden afectar a todos los materiales de la vidriera. La fatiga del hormigón está gobernada por un proceso de microfisuración interna que tiene como resultado la modificación de las propiedades mecánicas, en particular, la reducción de la rigidez y el crecimiento de las deformaciones totales y residuales en función del nivel de la tensión. La acción repetida conlleva la propagación y crecimiento de las fisuras, hasta que se produce la rotura repentina del material. En el vidrio, como ya vimos en el apartado 4, es la aparición de fracturas en los paneles inferiores de grandes vidrieras a causa del estrés por una carga continuada de peso.

\section{- El tiempo de exposición o factor cumulativo}

Ambos factores son consecuencia de una exposición a determinadas condiciones agresivas prolongadas en el tiempo, y el resultado de un fenómeno cumulativo, como la corrosión de vidrios, fracturas en el hormigón, oxidación de armaduras internas de hierro y marcos de soporte.

\section{— Deterioro del hormigón y corrosión de las armaduras internas}

Una de las propiedades más interesantes del hormigón es su carácter protector de las armaduras metálicas frente a la corrosión gracias a la alta alcalinidad que aporta la hidratación de la pasta de cemento $(\mathrm{pH}>13)$, incluso en presencia de humedad y oxígeno. Ahora bien, si el hormigón pierde su carácter básico $(\mathrm{pH}<9)$, la película protectora pierde efectividad en las zonas próximas a las armaduras internas y 
puede verse afectada por fenómenos corrosivos. La corrosión de las armaduras internas supone un punto de no retorno y nos obliga a actuar de manera directa sobre la obra, iniciando su desmontaje y traslado al taller para su estudio y posterior reparación. Si la corrosión está en un estado avanzado será necesario sustituir todo el hormigón, lo cual supone una operación de gran envergadura. [figura 9]

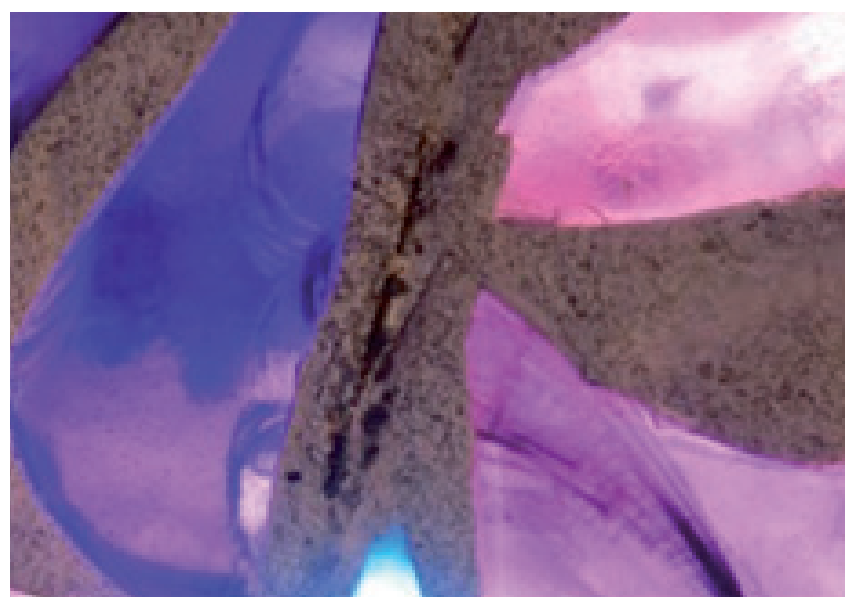

Figura 9.- Detalle corrosión armadura.

Las patologías más habituales del hormigón y las armaduras son la carbonatación y la presencia de sales (cloruros).

- Carbonatación: Este proceso se produce cuando el dióxido de carbono del aire reacciona con el hidróxido de carbono del hormigón, volviéndose el hormigón más duro y reduciendo su alcalinidad, lo cual, eventualmente, produce la corrosión de la armadura.

Indicador de $\mathrm{pH}$ por disolución de fenolftaleína: El indicador de $\mathrm{pH}$ de fenolftaleína permite diferenciar tres zonas de $\mathrm{pH}$, inferior a 8, donde la disolución se torna incolora, entre 8 y 9,5, donde adquiere una tonalidad rosa suave, y mayor de 9,5 , donde adquiere un color rojo púrpura intenso. En la prevención de la corrosión del hormigón armado la coloración por fenolftaleína es una técnica muy utilizada ya que a $\mathrm{pH}$ por debajo de 8 el acero se puede corroer, mientras que a $\mathrm{pH}$ muy alcalinos se encuentra pasivo. A la profundidad que alcanza la zona de pH inferior a 8, zona incolora, se le suele llamar'profundidad de carbonatación. La aplicación se

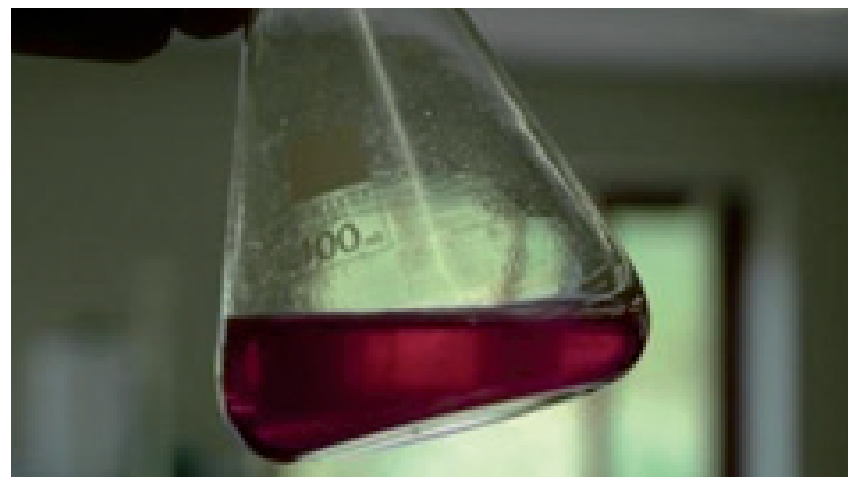

Figura 10.- Disolución de fenolftaleína realiza mediante un pulverizador disolviendo la fenolftaleína al $1 \%$ en alcohol etílico, en pocos minutos se produce la coloración de las diferentes zonas. [figura 10]

- Sal (cloruros): Los problemas causados por la sal se suelen deber al contacto permanente con agua salina. El cloruro reduce el valor del $\mathrm{Ph}$ del agua, lo que puede producir corrosión en la armadura y daños significativos al hormigón. En la línea de costa, la brisa marina arrastra importantes contenidos de humedad que, naturalmente, lleva en sí cloruros; de esta manera, estructuras que no están en contacto directo con el agua de mar, sufren igualmente sus embates.

Podríamos concluir que los problemas de conservación derivados por carbonatación y por cloruros son dos de las patologías más graves de deterioro y que suelen ser comunes en la mayoría de las vidrieras de hormigón que utilizan el hormigón armado tradicional. Esto se agrava por la insuficiencia de recubrimiento del armazón interno y supone una velocidad de carbonatación cuatro veces mayor.

Para combatir algunos de estos problemas aquí mencionados, recomendamos: Relaciones agua/cemento bajas, el empleo de cementos con aditivos aireante, un curado adecuado, armadura metálica de acero inoxidable 316 (no necesita imprimación anticorrosiva), Tratamientos preventivos (apartado 5) Sikagard -670 W (pintura de protección frente a la carbonatación), Armaduras metálicas de acero con una Imprimación anticorrosiva monocomponente basada en resinas epoxídicas y zinc para la protección de armaduras, como por ejemplo Nitoprime Zincrich Plus ${ }^{\circledR}$.

\section{— Fisuras en el hormigón}

Las fisuras en el hormigón pueden generarse tanto como resultado del propio proceso de mezcla y aplicación (curado deficiente, exceso de cemento en la composición, falta de vibración, excesivo calor, etc., por las condiciones del edificio (defectos estructurales del propio edificio, fatiga de los materiales, etc.) o durante su instalación (transporte inadecuado de las vidrieras, errores en su colocación, falta de junta de dilatación, sellado inadecuado, etc.) Estos daños pueden clasificarse en dos grupos: daños no estructurales (se producen tanto durante el estado fresco como durante el endurecimiento) y daños estructurales (resultado de acciones mecánicas que sufre la estructura del edificio).

Normalmente estas fisuras no afectan estructuralmente al material, pero sí suponen una puerta abierta a los agentes exteriores que puede aparecer cuando un material ha superado la tensión que es capaz de soportar, de ahí la importancia de conocer cuáles son las patologías que sufre el hormigón, paso previo y necesario para la aplicación de una solución adecuada. [figura 11] 


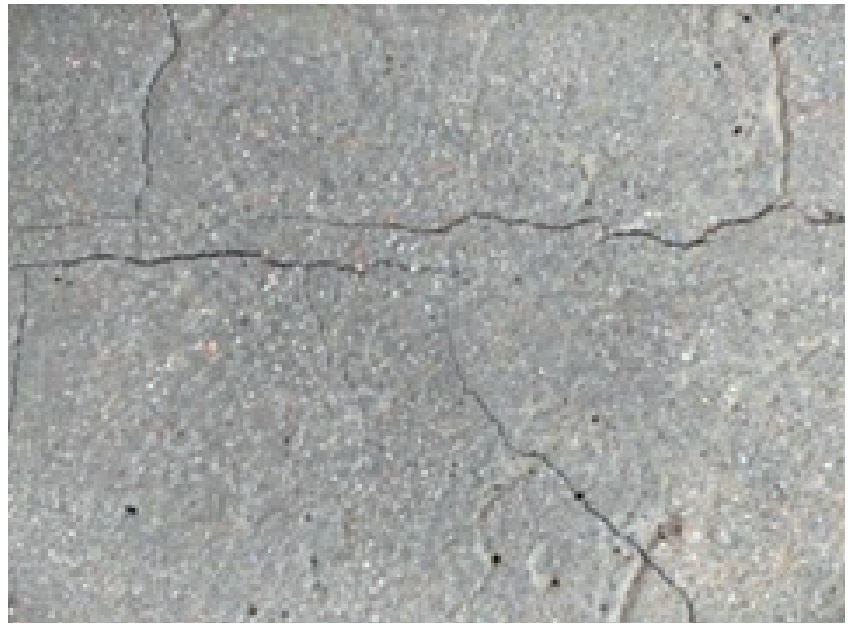

Figura 11.- Detalle fisuras

\section{Conservación y restauración de vidrieras de hormigón}

Lamentablemente, como ya hemos mencionado anteriormente, son muy escasos los estudios científicosexperimentales en el campo específico de la Restauración y Conservación de las vidrieras de hormigón. Tampoco disponemos de una serie de protocolos o directrices básicas de actuación, como las que podemos encontrar en el caso de las vidrieras emplomadas. En este sentido es necesario recordar que las Líneas Directrices del CVMA no cuentan con la aprobación y respaldo oficiales de las diferentes administraciones públicas, paso este absolutamente necesario para mejorar la situación actual en la conservación y restauración de vidrieras en España.

La solución a una parte de los problemas a los que se enfrenta el campo de la conservación-restauración de bienes culturales en la actualidad pasa por la formación de equipos interdisciplinarios que trabajen desde una perspectiva más diversificada, enriquecedora y completa. Solo mediante el trabajo en equipo podemos lograr un mejor análisis de los materiales y entender sus patologías, impulsar el desarrollo de nuevas técnicas y productos al servicio de la conservación, avanzar en el conocimiento de métodos y procedimientos que minimicen la acción de los agentes responsables del deterioro, asesorar en tareas de conservación y restauración, así como establecer sistemas, protocolos de trabajo y pautas o criterios de intervención. Finalmente, es esencial hacer una divulgación de esta actividad investigadora a través de publicaciones, participación en congresos, seminarios, coloquios y otras actividades similares que contribuyan a la formación de especialistas y al intercambio de conocimiento a nivel nacional e internacional.

Esta realidad, junto a un mayor incremento de las vidrieras de hormigón que necesitan ser conservadas y restauradas, genera a los talleres especializados en ésta técnica artística, una serie de incertidumbres a la hora de afrontar una nueva restauración. En base a la propia experiencia adquirida, los escasos estudios publicados y a la información compartida con colegas de profesión, intentamos solventar estas incertidumbres con el máximo respeto y preservación de los valores originales de cada obra.

Creo apropiado complementar la siguiente exposición con un artículo escrito por Fernando Cortés Pizano, "Principales actuaciones de Conservación- Restauración de vidrieras Históricas", y publicado en el 2015 en la revista N8 de GeConservación, donde hace una revisión de los métodos, productos y criterios más comúnmente utilizados hoy en día en la restauración de vidrieras tradicionales emplomadas. Se analiza de forma cronológica el proceso de intervención de una vidriera tradicional, desde las actuaciones iniciales de desmontaje, embalaje, transporte, almacenaje y documentación, hasta su restauración y transporte final, además de la protección mediante un adecuado sistema ventilado. El tipo de intervenciones descritas se centra principalmente en vidrieras históricas situadas en un contexto arquitectónico, y realizada con la técnica tradicional de vidrios emplomados, pero que perfectamente podemos adaptar, a excepción del apartado de restauración, a las vidrieras de hormigón, desarrollando una metodología similar de trabajo en muchos de los procesos de intervención descritos.

Otra particularidad que creemos conveniente mencionar en relación a los criterios de intervención es la referente a las restauraciones in situ o en taller. En el caso de las vidrieras tradicionales emplomadas generalmente se aconseja su traslado al taller, excepto en el caso de pequeñas reparaciones de emergencia o de mantenimiento. Pero en las intervenciones sobre vidrieras de hormigón, el desmontaje y posterior traslado al taller para su restauración, se considera una operación de emergencia, sólo necesaria para aquellas vidrieras en las que su estado de degradación ha llegado a una situación límite, no pudiéndose solucionar con ningún tratamiento correctivo in situ. Asimismo, el traslado al taller también podría ser necesario en aquellas vidrieras en las que gracias a las tareas de mantenimiento periódicas, se detecten patologías de degradación expansiva originadas por factores externos, como pueden ser las generadas por las condiciones del edificio o por una insuficiente junta de dilatación, incapaz de absorber los movimientos estructurales.

Con esto, no queremos decir que para llevar a cabo cualquier tipo de tratamiento preventivo o correctivo, como explicaremos a continuación, resulte más efectivo realizarlo "in situ", sin desmontar la vidriera. En cada intervención hay que saber valorar si las patologías detectadas se limitan a un único panel, conjunto de paneles o a toda la vidriera, y en consecuencia estudiar el modo de fijación, la complejidad de la intervención, el posible riesgo de intensificar los daños existentes $y$, como no, los costes del desmontaje. Toda esta información nos será sin duda de gran ayuda a la hora de actuar sobre la vidriera de la manera más segura, eficiente y responsable.

A continuación voy a proponer una serie de directrices básicas de actuaciones muy concretas y centradas 
exclusivamente en los materiales, con el deseo que, de alguna manera, puedan ayudar a allanar el camino a seguir en futuros estudios sobre este tema.

Por último analizaremos cómo afrontar la reconstrucción de lagunas, producidas generalmente por actos vandálicos o impactos fortuitos.

\section{Actuaciones de restauración y conservación sobre el hormigón}

\section{- Tratamientos preventivos}

En el caso de vidrieras históricas, la protección del hormigón por medio de la aplicación de sistemas eficaces constituidos por pinturas, barnices y revestimientos, los cuales ofrecen resistencia química y física ante las acciones de los agentes atmosféricos $u$ otras agresiones a las que la obra está sometida, es sin duda una opción de conservación preventiva muy interesante. Estos trabajos de protección pueden asimismo ser ejecutados preventivamente en las vidrieras de nueva creación, como parte de las actividades de mantenimiento correctivo, contribuyendo de forma decisiva a aumentar su vida útil, aplicándose en estos casos por las dos caras de la vidriera. En vidrieras ya instaladas priorizaremos estas actuaciones a la cara externa y siempre que sea posible, por accesibilidad o presupuesto, se intervendrá por las dos caras.

En relación con lasoperaciones periódicas de mantenimiento de la vidriera, estos sistemas de protección deberán ser controlados para así constatar su funcionalidad y verificar si necesitan ser renovados. Los objetivos básicos de su utilización son reducir la absorción de agua, la penetración de gases agresivos, sales, y, en algunos casos, utilizar las propiedades de ciertos materiales para actuar como barrera protectora contra el ataque de posibles elementos químicos agresivos.

Los sistemas de protección superficiales del hormigón pueden clasificarse en dos grandes grupos:

\section{- Impregnación hidrófuga}

Se logra una superficie cubierta y repelente al agua, no obstante el interior de sus poros y capilares no están rellenos y su aspecto no resulta alterado. Principalmente están compuestos por silanos o siloxanos. Su finalidad principal es la de reducir la absorción de agua por el hormigón, ya que, sin agua, no puede deteriorarse químicamente el hormigón. $\mathrm{Su}$ desventaja principal es el hecho de que no ofrecen ninguna protección química o mecánica al hormigón al no impedir la entrada de agua si el hormigón se fisura.

Productos más comúnmente utilizados: Sikagard ${ }^{\circledR}-917$ W es una emulsión, base siloxano, hidrofugante y repelente al aceite que se suministra lista para su uso, Weberneto $\mathbf{S 4 0 0}$
Penetra profundamente en los capilares ofreciendo una hidrofugación de máxima efectividad prolongando la vida útil del material tratado y previniendo el crecimiento de microorganismos. Es asimismo efectivo en el tratamiento contra la carbonatación de hormigones y morteros.

\section{— Impregnación de sellamiento o pinturas de protección}

Se reduce la porosidad superficial y se consolida la superficie mejorando el anclaje del recubrimiento. Los poros y capilares están parcial o completamente rellenos. Los principios activos suelen ser polímeros orgánicos. Son productos líquidos que forman una fina película sobre el hormigón y, a diferencia de los hidrofugantes transparentes, consolidan la primera capa superficial del hormigón y tienen una mayor durabilidad. Pueden utilizarse durante la fase de curado del hormigón o por impregnación una vez fraguado. Las pinturas y barnices a base de poliuretano son más duraderos y alargan la vida útil del hormigón, reduciendo los problemas por carbonatación al eliminar la absorción de agua.

Propiedades: reducen significativamente la carbonatación, limitan la permeabilidad e inhiben el crecimiento de hongos y bacterias.

Productos más comúnmente utilizados: Sika ferroGard -903 plus. Es un inhibidor de la corrosión por impregnación. Tratamiento de control de corrosión para hormigón sin daños, donde el acero de refuerzo se corroe o está en riesgo de corrosión debido a los efectos del hormigón carbonatado o contaminado con cloruro. Se puede usar como un sistema de reparación y protección del hormigón.

Sikagard $-670 \mathrm{~W}$. Es una pintura de protección frente a la carbonatación, monocomponente, a base de resinas acrílicas. Excelente resistencia a la intemperie y al envejecimiento. Impermeable al agua de Iluvia. Color blanco, gris piedra y sobre pedido.

\section{- Tratamientos correctivos}

La situación más común es que las operaciones de mantenimiento sean correctivas, donde a partir de manifestaciones de lesiones patológicas y de la realización de un diagnóstico previo del problema para la identificación de las causas se procede a la corrección y protección del hormigón. Existen técnicas adecuadas de corrección y productos de conocida eficacia, los cuales deben ser usados sobre el hormigón previamente a recibir la nueva pintura de protección.

La pérdida de alcalinidad o contaminación por cloruros en el hormigón constituye una problemática que puede comportar problemas graves para el sistema estructural en su conjunto. Pero donde el problema se vuelve realmente delicado es en la armadura, en la cual, al 
quedar desprotegida químicamente o al ser atacada por los iones de cloruro, se producirá un proceso de corrosión generalizado. Los síntomas principales de esta corrosión expansiva son las fisuras, oquedades, fracturas de las dallas y hasta desprendimientos en la superficie del hormigón, los cuales evidencian los verdaderos problemas que se generan en su interior.

Para evitar llegar a estas situaciones límite lo aconsejable es tratar de evitar la corrosión de la armadura durante la ejecución de la estructura. En el caso de las estructuras existentes también podemos actuar preventivamente, sin que sea necesario esperar a la aparición de los primeros síntomas de la corrosión. Abordar este problema, una vez iniciada la corrosión, resulta realmente difícil. La solución que se viene aplicando, siempre que nos encontramos en una fase inicial y no generalizada de la corrosión es intentar reducir su velocidad de propagación e incluso parar completamente el proceso de corrosión de la armadura, actuando sobre el verdadero problema evitando que se produzca la corrosión en primer lugar.

Estas técnicas se disponen en 4 etapas diferentes de intervención: Eliminación del hormigón deteriorado, Reparación de fisuras, Aplicación morteros de reparación, Sistemas de protección superficiales.

\section{— Eliminación del hormigón deteriorado}

El proceso se realizará con medios manuales o automáticos $\left(\right.$ Dremel $\left.^{\circledR}\right)$ y consiste en la extracción de todos los fragmentos del hormigón deteriorado, como consecuencia de la expansión de la armadura en su proceso de corrosión, de una mala calidad del hormigón, de fases de congelación o de movimientos estructurales. De esta forma se retira todo el material suelto o mal adherido hasta alcanzar el hormigón sano. Toda esta operación debe realizarse con sumo cuidado de no perjudicar la integridad estructural de la vidriera que se encuentra en una situación muy vulnerable.

\section{- Reparación de fisuras}

Antes de proceder a la recomposición de la sección con el nuevo material se debe observar la superficie que ha quedado descubierta para detectar futuras fisuras. En el caso de que existan es importante conocer las causas que permitieron su formación y estar seguros de que no siguen presentes para evitar realizar la reparación de una patología que pueda volver a aparecer. En todos los casos de fisuración las resinas epoxi han demostrado ser adecuadas para realizar el sellado y, mediante la unión, convertir de nuevo en monolíticos los elementos estructurales separados por los planos de las fisuras. Se recomiendan los siguientes tipos de resinas epoxi en función de la anchura de la fisura:

Inferiores de 0,5 mm/mm: A veces no son visibles a simple vista. Generalmente, no implican problemas estructurales, pero pueden provocar consecuencias más graves como permitir la entrada de agentes agresivos que pueden corroer las armaduras internas. Utilizar resinas epóxicas bicomponentes de viscosidad igual o inferior a $500 \mathrm{cp}$.

-Entre $0,6 \mathrm{~mm} / \mathrm{mm}$ y $3 \mathrm{~mm} / \mathrm{mm}$ : formulaciones epoxi bicomponentes puras o cargadas con polvo de cuarzo o de vidrio, pero con viscosidad inferior a 1500cp. La especificación de la ASTM C881, identifica los criterios básicos para la selección del grado y clase de resinas a usar.

\section{- Aplicación de morteros de reparación}

Sika monotop 612 es un mortero de reparación estructural de un componente reforzado con fibras y humo de sílice que cumple con los requerimientos de la clase R3 de la UNE-EN 1504-3. Se trata de un mortero preparado, listo para su empleo con la sola adición de agua y de fácil aplicación en superficies verticales. Se adhiere perfectamente sin imprimación, es adecuado para trabajos de refuerzo estructural y restituye el hormigón contaminado por carbonatación. De esta manera se conseguirá que la zona de hormigón reparada tenga la resistencia, la inercia y la durabilidad suficientes, equiparables a sus prestaciones originales, que es el objetivo cuando se hace una reparación.

\section{— Sistemas de protección superficiales}

Actuar como si se tratara de un tratamiento preventivo, aplicando tratamientos de impregnación hidrófuga, selladora o pinturas de protección sobre toda la superficie del hormigón de la vidriera.

\section{— Desmontaje y restauración en taller}

Casi todas las vidrieras de hormigón que llegan a un estado límite de conservación donde se llega a cuestionar su integridad estructural y la seguridad de las personas, tienen en común una suma de patologías de degradación, las cuales, a su vez, se retroalimentan mutuamente, siendo realmente difícil, llegados a este punto, repararlas con tratamientos correctivos. Se precisa de un estudio muy detallado y respetuoso para determinar si una vidriera de hormigón ha alcanzado ese punto de no retorno que implica su desmontaje y traslado al taller para proceder a un tipo de actuación más agresiva, que implica en la mayoría de los casos la sustitución del hormigón y, a menudo, muchas de las dallas.

La dificultad y costos, junto a la posibilidad de roturas a la hora de desmontar una vidriera o conjunto de paneles, debe ser siempre la última opción que ha de ser planteada sólo en aquellos casos donde la integridad estructural está realmente degradada, evidenciando un riesgo claro para la obra y para la seguridad de las personas por el riesgo inminente de desprendimientos. 
Los fenómenos que observamos en estos casos a simple vista suelen ser grietas, desprendimientos de mortero, expansión de las armaduras, vidrios con múltiples fracturas y roturas, incluso en casos extremos, deformaciones en la planimetría de los paneles.

\section{- Procedimiento}

Previo al desmontaje, trabajaremos por la cara donde se instaló la vidriera a la obra o a la estructura-marco de acero, asegurándonos de sacar fotografías de todas las zonas dañadas y de todos los paneles que vayan a ser desmontados, así como obtener plantillas de toda la vidriera. Será suficiente con un papel vegetal marcando la forma de todos los vidrios, enumerándolos y anotando su color correspondiente.

Aseguraremos los paneles con una malla pegada con una disolución de cola blanca y agua a toda la superficie para evitar desprendimientos y así garantizar su integridad y seguridad durante su manipulación. Si tenemos acceso a la cara opuesta también recomendamos realizar la misma operación. Sobre esta malla también enumeraremos cada panel de manera que sepamos el lugar concreto que ocupa.

Teniendo en cuenta como se fijaron los paneles entre sí y a la obra iniciaremos su desmontaje comenzando de abajo

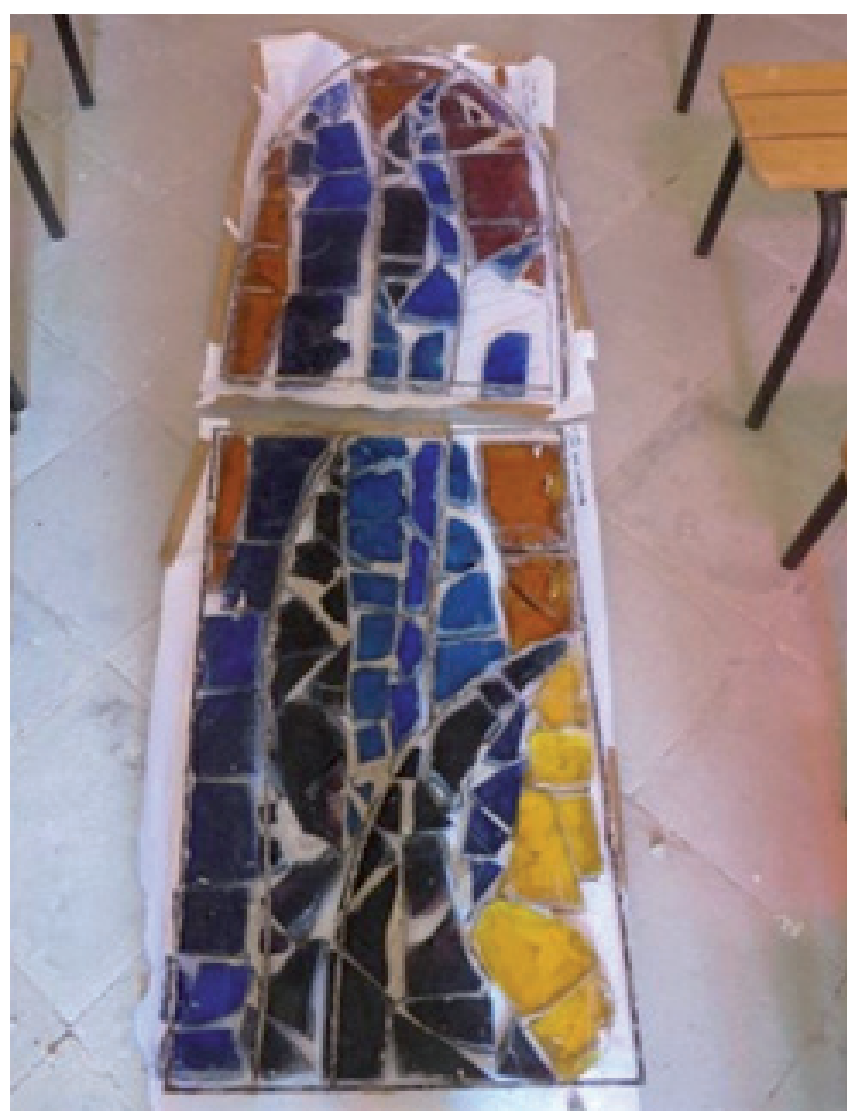

Figura 12.- Chapelle de Montalaurou - Pailhès. (Carlo Roccella) hacia arriba, excepto en aquellos casos de superposición de paneles donde se iniciará siempre por la parte superior. Deberán de tomarse todas las medidas de seguridad pertinentes por el riesgo elevado de desprendimientos por ambas caras de la vidriera.

Una vez en el taller, seleccionaremos los vidrios que se encuentren en buen estado para su reutilización en la nueva vidriera eliminando todo el hormigón y armaduras originales. Dataremos todos los vidrios nuevos para diferenciarlos de los originales. [figura 12]

Como se comentó en el apartado de realización de una nueva vidriera, debemos tener muy en cuenta las particularidades de cada proyecto y decidir correctamente la elección de materiales, técnicas de fabricación y procedimientos de ejecución, ya que estas decisiones afectarán a la vidriera durante toda su vida útil. Los nuevos paneles restaurados se diseñarán teniendo en cuenta la nueva estructura de acero que los soportará.

\section{Actuaciones de restauración y conservación sobre las dallas}

La aparición de fracturas en los vidrios puede ser causada por estrés o factores internos (composición o manufactura incorrecta del vidrio) o por estrés o factores externos (carga de peso, falta de juntas de dilatación, impactos, corrosión de las armaduras internas o una insolación excesiva). Las roturas cambian la forma en que la luz incidente interactúa dentro del vidrio creando una refracción, cambio de dirección que provoca una pérdida de transparencia. También dan como resultado un aislamiento más deficiente y una pérdida de estabilidad. La intervención sobre cualquier fractura o rotura de los vidrios conlleva una investigación preliminar con el fin de adquirir la información necesaria para determinar y dar solución a las causas responsables de la fractura antes de proceder a su restauración

\section{- Reparación de fracturas}

Los limitados estudios realizados para la consolidación de fracturas o roturas de los vidrios mediante adhesivos y consolidantes no han sido suficientes para conseguir un tratamiento efectivo que dé solución a los diferentes retos a tener en cuenta: reversibilidad de los materiales, propiedades de envejecimiento (coloración amarillenta, fragilidad), facilidad de tratamiento (una o varias capas) o neutralización del efecto reflectante de las superficies internas.

El mayor problema de consolidación del vidrio es que debe penetrar piezas de vidrios de varios milímetros de grosor, entre $20 \mathrm{~mm}$ y $30 \mathrm{~mm}$, además de aplicarse in situ, en vertical, donde el uso de jeringuilla se ha demostrado poco efectivo. 
De entre los adhesivos seleccionados en el proyecto CONSTGLASS ninguno se considera adecuado, ni el adhesivo ni la técnica de aplicación y se requiere más investigación. Sólo el Paraloid B-72 (5\% en peso) y el LV740 destacaron entre los demás, aunque su penetración y técnica de aplicación in situ es insuficiente.

Por lotanto, los conservadores-restauradores deben seguir un proceso de razonamiento para determinar si la consolidación de las roturas y grietas es absolutamente necesaria para evitar una mayor descomposición o pérdida de vidrio. Una posible intervención de emergencia podría ser la aplicación de un tejido de seda $\left(20 \mathrm{~g} / \mathrm{m}^{2}\right)$ a la superficie del vidrio por medio de un consolidante reversible como Paraloid ${ }^{\circledR}$ B-72 u ORG ${ }^{\circledR}$. El consolidante también se infiltrará en las roturas y grietas, y esta infiltración será restringida a varios $\mathrm{mm}$ solamente, permitiendo futuros tratamientos de reversibilidad. Además, la tela de seda de vidrio es prácticamente invisible in situ. Esta técnica aún se está investigando en el contexto de la prevención-conservación de vidrios del siglo XIX susceptibles de fracturarse como resultado de su composición química. Para ello se llevó a cabo un experimento en un vidrio de una vidriera de hormigón ubicada en el estudio de conservación de vidrieras de la Universidad de Amberes, en Bélgica, como parte de nuevas investigaciones sobre el comportamiento a largo plazo del vidrio restaurado, teniendo en cuenta aspectos tales como reversibilidad y re-tratabilidad de las intervenciones y productos aplicados.

\section{- Reparaciones de actos vandálicos o impactos fortuitos}

Las lesiones que puede recibir una vidriera de hormigón por el impacto violento de un objeto sobre uno de sus paneles, ya sea fortuito o premeditado, puede provocar daños muy graves, aunque al contrario de las anteriores, pueden ser muy localizados, sin llegar a generar un problema de integridad estructural generalizada, pudiendo generalmente ser restaurada "in situ". No obstante, la reparación de este tipo de obras requiere una actuación rápida por el riesgo de evitar un mayor deterioro del resto de la vidriera.

Estas reparaciones requieren otro planteamiento, que consiste generalmente, en estudiar detalladamente el grado de afectación tanto de la zona afectada como del conjunto del panel. Si la estructura del panel es estable sería posible intervenir in situ sobre la zona deteriorada. [figura 13]

En estos casos se procede a obtener una plantilla de la zona a sustituir, retirar íntegramente todo el material deteriorado utilizando medios mecánicos, (amoladora o Dremel ${ }^{\oplus}$ ), todo ello con el máximo cuidado para no dañar el conjunto de la vidriera. Recuperaremos todos los vidrios que se encuentren en buen estado y los incorporaremos al nuevo fragmento de vidriera. Si se incorporan nuevos vidrios serán identificados por la cara interior utilizando una punta de diamante o una Dremel $^{\circledR}$. [figura 14]

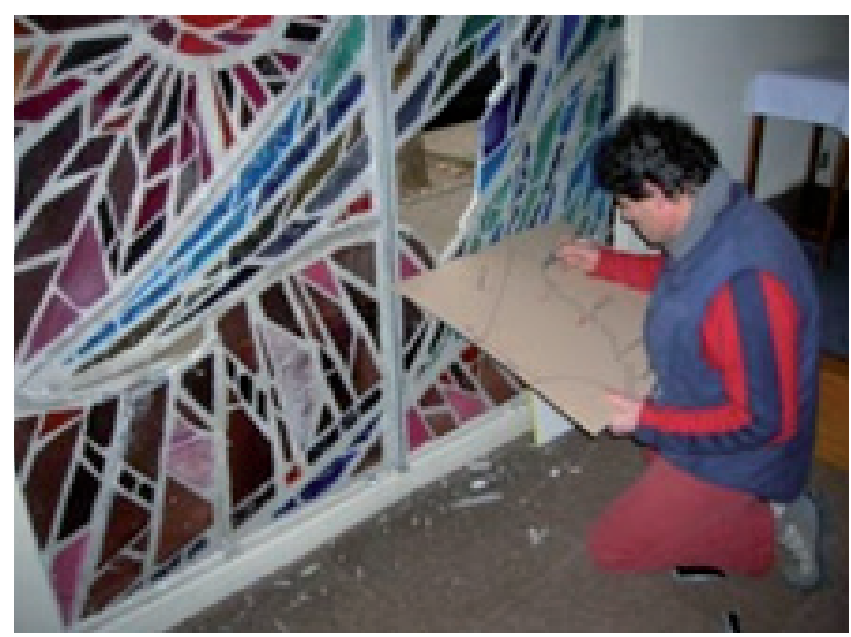

Figura 13.- Iglesia Don Bosco. Montpellier. (Carlo Roccella)

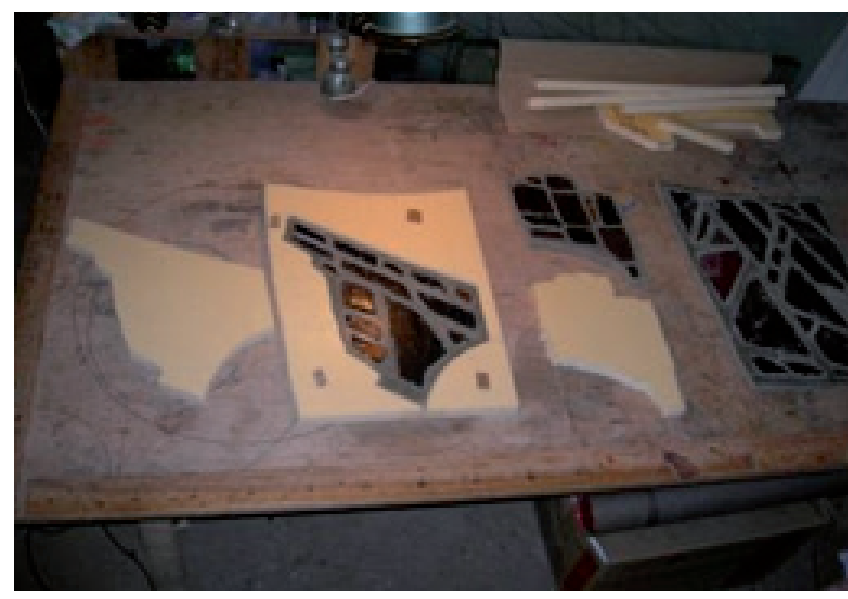

Figura 14.- Iglesia Don Bosco. Montpellier. (Carlo Roccella)

El nuevo fragmento deberá encajar en la vidriera con una junta perimetral de $1 \mathrm{~mm}$ que será rellenada con resina epoxi como si se tratara de una reparación de fisuras.

Las decisiones a favor o en contra del reemplazo (parcial) de determinadas piezas de vidrio pueden depender de factores artísticos, argumentos históricos, estéticos y funcionales que deben saber valorarse en cada caso en particular. El artículo 12 de la Carta de Venecia nos dice: "los reemplazos deben integrarse armoniosamente con el conjunto pero al mismo tiempo deben ser distinguibles del original".

\section{Agradecimientos:}

Muy especialmente a Fernando Cortés Pizano, por su motivación, consejos y preciadas aportaciones tanto en corrección-redacción de texto como en estructura. A mi colega vitrallista, también creador y restaurador de vidrieras de hormigón, Carlo Roccella, por su generosidad y confianza, compartiendo sus proyectos y ámplia experiencia para la realización de este artículo. Y a mi mujer Ariadna, por su apoyo continuo para que yo tuviera el tiempo y la dedicación para la realización de este proyecto. 


\section{Referencias}

CAEN, J. JANSSENS,k. JACOBS, P. (2014). The Consolidation of Architectural Glass and Dalle de Verre; Assessment of Selected Adhesives. Antwerpen. Faculteit Ontwerpwetenschappen

CORTÉS PIZANO, F. (2015). Principales Actuaciones en la Conservación - Restauración deVidrieras. Ge-Conservacion, 8: 122-133. https://doi.org/10.37558/gec.v8i0.298

GALÁN GARCIA, I. (2012). Carbonatación del hormigón. Madrid. Tesis de la Universidad Complutense de Madrid, facultad de Ciencias Químicas.

GONZÁLEZ LUCAS, A. (2014). Comportamiento frente a la durabilidad de morteros de reparación de cemento modificados con Polímeros. Madrid. Universidad Politécnica de Madrid.

KRISTEL DE VIS, JOOST CAEN, KOEN JANSSENS y PATRIC JACOBS. (2013). The Consolidation of Cracks and Fissures in Dalle de Verre: Amsterdam. Forum of the International Scientific Committee for the Conservation of Stained Glass (Corpus Vitrearum-ICOMOS).

KRISTEL DE VIS, JOOST CAEN, KOEN JANSSENS, PATRIC JACOBS. (2015). The Consolidation of Cracks and Fissures in Dalle de Verre: Assessment of Selected Adhesives. Netherlands. @lcom Committee for conservation.

PEPI, RAYMOND M. (2014). Conservation of Dalle de Verre at the New York Hall of Science. Springfield. Association of Preservation Technology International.

PORTO QUINTIÁN, J. (2005). Manual de Patologías en las estructuras de hormigón armado. La Coruña. Universida de da Coruña. Escola Universitaria de Arquitectura

ZANUY, C. ALBAJAR, L. DE LA FUENTE, P. (2011). El proceso de fatiga del hormigón y su influencia estructural, en Materiales de construcción. Madrid. Universidad Politécnica de Madrid.

https://blog.sagradafamilia.org/es/especialistas/la-resina-epoxi/

https://proasur.com/es/nosotros/actualidad/resina-en-losprocesos-productivos-de-proasur/

\section{Autor/es}

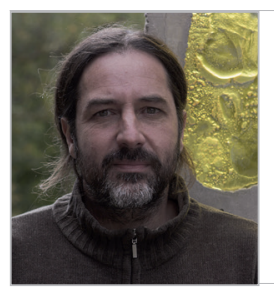

\section{Pepe Cubillo}

info@mondovitral.com

Arcobe

Artesano del vidrio con taller propio, Mondovitral, desde el año 2002. Especializado en la Creación, Restauración y Conservación de vidrieras. En 1995 tuvo su primer contacto con el vidrio artístico, trabajando durante 5 años en el taller de Antonio Luis Sainz "Keshava", en Barcelona. Durante los años 2000-2002 completó sus conocimientos estudiando en la Fundació Centre del Vidre de Barcelona técnicas aplicadas a la vidriera contemporánea. Gracias a la generosidad de Antonio Callejón, propietario de la empresa de vidrio soplado Regiopistrina en Molins de Rei, y con una extensa trayectoria en la realización de vidrieras de hormigón, aprendió la técnica para la elaboración de este tipo de vidrieras. En el año 2018 recibió el premio Restaura de la mano del President de la Generalitat de Catalunya, un reconocimiento por la restauración integral del Portal de la Boqueria de Barcelona. En esta obra coordinó y dirigió su propio equipo multidisciplinar que intervinieron en la restauración. Actualmente forma parte de la junta directiva de Arcove y coordina la comisión centrada en la catalogación e inventario de vidrieras de España.

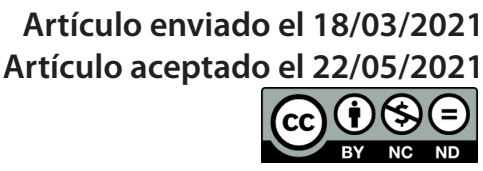

https://doi.org/10.37558/gec.v19i.977 